\title{
Pengaruh Profitabilitas, (Roa), Ukuran Perusahaan, Likuiditas, Pertumbuhan Penjualan Dan Struktur Aset Terhadap Kebijakan Hutang
}

\author{
Andrianti ${ }^{1}$, Dirvi Surya Abbas ${ }^{2}$, Mohamad Zulman Hakim ${ }^{3}$ \\ Universitas Muhammadiyah Tangerang ${ }^{123}$ \\ Email Korespondensi : antiandri724@gmail.com
}

\begin{abstract}
Abstrak: Penelitian ini di lakukan dengan tujuan untuk mengetahui pengaruh Profitabilitas, Ukuran Perusahaan, Likuiditas, Pertumbuhan Penjualan dan Struktur Aset Terhadap Kebijakan Hutang Pada Perusahaan Infrastructure, Utilities, And Transportation yang terdaftar di Bursa Efek Indonesia (BEI). Khususnya periode tahun 2014 - 2018 sebagai Populasi Penelitian.

Metode Sampling yang di gunakan dalam penelitian ini adalah metode Purposive Sampling dengan total Sample 50 data perusahaan yang merupakan data yang di ambil dari Laporan Keuangan yang berasal dari www.idx.co.id. Metode analisis yang di gunakan yaitu Metode analisis regresi data panel.

Hasil penelitian ini menunjukan bahwa Ukuran Perusahaan, dan Pertumbuhan Penjualan memiliki pengaruh positif terhadap Kebijakan Hutang, dan Profitabilitas, Likuiditas, dan Struktur Aset memiliki pengaruh yang negatif terhadap Kebijakan Hutang.
\end{abstract}

Kata Kunci : Profitabilitas; Ukuran Perusahaan; Likuiditas; Struktur aset; Kebijakan Hutang

Kebijakan Hutang merupakan salah satu sumber pendanaan external yang digunakan oleh perusahaan untuk membiayai kebutuhan dana, namun di lain hal penggunaan hutang dapat meningkatkan nilai perusahaan, karena perusahaan dianggap memiliki kemampuan dan prospek yang bagus oleh investor. Kebijakan hutang akan memotivasi pihak manajer demi makin berwaspada saat memaksimalkan penggunaan budjet tersebut, sebab demi hutang sampai-sampai indsutri mempunyai komitmen untuk melakukan penyetoran atas tambahan dan pinjaman pokoknya menurut berkala. Manajer juga harus memperhatikan dan mempertimbangkan keuntungan serta kerugiannya karena kegagalan perusahaan dalam melunasi hutang dapat mengancam likuiditas perusahaan. (Trisnawati, dkk, 2017 dalam Tharob,2018)

Menurut (Sheisarvian, 2015), menerebitkan kebijakan hutang indudtri sangat tidak gampang sebab dalam industry ditemukan jumlah pihak yang mempunyai wewenang yang berlainan sehingga penciptaan kesimpulan tak bisa terbebas dari friksi keagenan yang terjadi dalam perusahaan. Hubungan yang terjadi ini disebut dengan hubungan keagenan.

Menurut Jensen dan Meckling (1976) dalam (Indahningrum \& Handayani, 2009) prosedur akan mengendalikan friksi keagenan yakni menambah insider ownership sehingga mampu mensejajarkan keperluan pemilik sama manajer. Hutang ialah suatu metode lain yang dapat dipergunakan demi mengurangi atau memeriksa friksi keagenan. 
observasi ini dibuat demi mencari dampak atau factor apa saja yang bisa mempengaruhi kebijakan hutang. Variabel yang dipakai pada observasi ini yakni profitabilitas, Ukuran Perusahaan,likuiditas,pertumbuhan penjualan dan struktur asset terhadap Kebijakan Hutang .

Menurut Riyanto (2008, h.25) dampak yang berksangkutan pada kapasitas suatu industry akan sepatutnya terpenuhi dinamakan serupa dengan Likuiditas. berdasarkan observasi terakhir current ratio menurut Dinar Damayanti (2013) bawah current ratio mempunyai dampak negatif terhadap kebijakan hutang. Temuan ini seperti oleh theory yang dinyatakan sama Kasmir (2010:134) menuimpulkan bawah semakin banyak ratio lancar industri, maka industri membagikan kompetensi dalam memenuhi tanggung jawabnya. Hasil obseravi ini pun persis oleh observasi yang dilakukan oleh Mersi Narita (2012), mengatakan bawah current ratio mempunyai dampak negatif terhadap kebijakan hutang. Namun bagi hasil observasi menyebutkan bawah variabel current ratio (CR) berdampak positif dan signifikan terhadap kebijakan hutang

Pertumbuhan penjualan menurut Bringham dan Houston (2010),yang menyatakan bahwa tingkat tingginya keuntungan suatu perusahaan akan menjadikan perusahaan tersebut cenderung menjadikan utang sebagai sumber penghasilan yang lebih besar jika dibandingakn dengan perusahaan yang memiliki tingkat profit penjualan yang rendah. Hasil penelitian ini diperkuat oleh penelitian yang dilakukan oleh pradhana dkk. (2014) dan pithaloka (2013) yang menyatakan bahwa pertumbuhan penjualan tidak memiliki pengaruh apapun terhadap kebijakan hutang. Namun berbeda dengan penelitian terdahulu yang dilakukan oleh Amirya Dan Atmini (2008), yang menyatakan bahwa pertumbuhan penjualan mempunyai pengaruh negatif dan signifikan terhadap kebijakan hutang,tetapi penelitian ini berbeda dengan penelitian terdahulu yang dilakukan oleh Damayanti (2013) yang mengatakan bahwa pertumbuhan penjualan memiliki pengaruh yang positif terhadap kebijakan hutang.

Profitabilitas menggambarkan kapasitas industry dalam menadapatkan profit sehingga bisa mendanai aktivitas investasi industry masa lama. Myers (1984) dalam Indahningrum dan Handayani (2009) industry ketika membuat pendanaan aktivitas investasi mampu memprioritaskan pecking order yakni susunan penggunaan dana yang dari profit ditahan lalu diikuti oleh hutang dan ekuitas. Oleh karena itu, semakin tinggi profitabilitas perusahaan, akan mengurangi tingkat hutang. Berdasarkan penelitian terdahulu Profitabilitas menurut Astuti (2014) dan Sheisarvian dkk (2015) mempunyai pengaruh yang signifikan terhadap kebijakan hutang. Namun penelitian ini tidak sejalan dengan yang dilakukan oleh Nuraini (2014) bahwa profitabilitas tidak berpengaruh signifikan terhadap kebijakan hutang.

Ukuran perusahaan menggambarkan besar kecilnya suatu perusahaan, dimana hal tersebut digambarkan melalui sumber daya yang dimiliki suatu perusahaan. Sumber daya tersebut meliputi aset, teknologi, kekayaan intelektual, dan sebagainya menurut Sari dan Prasetiono (2015) 
dalam Tharob (2018). Menurut Astuti (2014) semakin besar ukuran perusahaan, diprediksikan memiliki tingkat hutang yang semakin tinggi. Berdasarkan penelitian terdahulu Ukuran perusahaan menurut Astuti (2014), (Ashraf \& Rasool, 2013) mempunyai pengaruh yang signifikan terhadap kebijakan hutang. Namun penelitian ini tidak sejalan dengan yang dilakukan oleh (Darmayanti \& Hartini, 2013) bahwa ukuran perusahaan tidak berpengaruh signifikan terhadap kebijakan hutang.

Struktur Aset yang telah di uji, menunjukan bahwa struktur asset ini memiliki pengaruh yang positif terhadap kebijakan hutang artinya semakin besar nilai aktiva lancar dalam jumlah aktiva, maka semakin besar pula pinjaman yang akan di peroleh oleh perusahaan. Tingginya jumlah aktiva tetap yang di peroleh perusahaan, maka semakin tinggi pula sumber daya perusahaan dalam mengabulkan kewajibannya terkait dengan pinjaman yang di peroleh. Hasil penelitian ini diperkuat oleh penelitian yang di lakukan oleh Hidayat (2013), Hardiningish dan Oktaviani (2012), Steve dan Lina (2011), dan Purnaningrum (2013). Namun berbeda dengan penelitian yang di lakukan oleh Yuniarti (2013), yang mengatakan bahwa Struktur asset tidak memiliki pengaruh terhadap kebijakan hutang. Tetapi lain pula dengan hasil penelitian terdahulu yang di lakukan oleh Deviani dan Sudjarni (2018) yang berpendapat bahwa Struktur Aset memiliki pengaruh negatif terhadap kebijakan hutang. Dimana hal ini mempunyai makna yakni semakin besar Struktur Aktiva maka, Debt to Equity Ratio akan semakin kecil. beberapa hal tentang kebijakan hutang yang berkaitan dengan kemampuan pihak manajemen dan para investor dalam pengambilan keputusan pendanaan, dan adanya fenomena yang diteliti dijadikan acuan dalam penelitian ini serta melihat ketidakkonsistenan hasil penelitian yang dilakukan oleh beberapa peneliti terdahulu tentang profitabilitas,ukuran perusahaan, likuiditas, pertumbuhan penjualan dan struktur asset yang menyatakan perbedaan hasil penelitian terhadap kebijakan hutang, maka peneliti ingin menguji kembali apakah variabelvariabel yang digunakan oleh peneliti nantinya terdapat perbedaan dari hasil penelitian terdahulu. Berdasarkan fenomena dan Research GAP maka peneliti mengambil judul "Pengaruh Profitabilitas, ukuran perusahaan,Likuiditas, Pertumbuhan penjualan, dan Struktur asset terhadap Kebijakan Hutang

Agar penelitian ini tetap pada tujuannya dan tidak menyimpang, maka penelitian ini perlu diberikan batasan agar lebih efektif. Peneliti membuat batasan bahwa sampel yang digunakan adalah Perusahaan Infratructure,Utilities And Transportation yang terdaftar di BEl. Variabel independen yang akan diteliti adalah profitabilitas,ukuran perusahaan,likuiditas, pertumbuhan penjualan struktur aset sedangkan variabel dependennya adalah kebijakan hutang.

\section{METODE}

Tipe data yang digunakan dalam observasi ini adalah data inferior yaitu data yang didapat secara tak serta merta dari sasaran observasi yang 
berasalr dari catatan keuangan, yang terdiri dari balans, laporan laba rugi, informasi keuangan dan data non akuntansi dari perusahaan Infrastructure ,utilities, And Transportation di BEl, dan tersedia secara online pada situs http://www.idx.co.id.

Penelitian ini menggunakan dua jenis variabel yang terdiri dari variabel dependen yaitu kebijakan hutang, variabel independen yaitu profitabilitas, ukuran perusahaan,Likuiditas, Ukuran Perusahaan dan Struktr asset. Dalam penelitian populasi yang di gunakan perusahaan perusahaan infrastructure,Utilities And Transportation yang terdapat di Bursa Efek Indonesia selama periode 2014-2018.Perusahaan Infrastructure,utilities And Transportation,dimana sudah menjadi kebutuhan untuk semua kalangan. Sample yang digunakan dalam penelitian ini adalah purposive sampling yaitu perusahaan yang samplenya dipilih berdasarkan tolak ukur tertentu dan secara tidak random dan disesuaikan dengan objek dan kasus. Industry yang besarannya mencukupi tolak ukur ialah sebanyak 10 industri. Periode observasi terhitung 5 tahun yakni tahun 2014-2018 sehingga jumlah data adalah 50 data. Berikut ini menggambarkan tolak ukur industry yang akan muncul sebagai ilustrasi. Ilustrasi dengan proses purposive sampling bakal difungsikan untuk sementara dalam observasi, yakni:

1. Indutri infrastructure, utilities and prasarana yang terdaftar di BEI sampai dengan tahun 2018

2. industri yang tidak menampilkan report keuangan komplit periode 2014 $-2018$

3. industry yang mengkalim kemalangan 2014-2018

4. industry yang tidak mencukupi tolak ukur yang di perlukan

5. industry yang mempunyai data outler periode 2014-2018

Penelitian dilakukan dengan menggunakan Metode analisis data kauntitatif dengan menggunakan Software Microsoft Excel 2010 untuk mengumpulkan data-data Financial statement perusahaan terkait dengan komponen-komponen yang digunakan untuk menghitung variabel dependen maupun variabel independen. Data diolah dengan menggunakan program Eviews 10.0 sebagai tools untuk menguji data yang tersedia. Penelitian ini menggunakan teknik pengolahan data berupa analisis stastisik deskriptif dan analisis regresi data panel.

\section{A. Kebijakan Hutang}

(Santi Herawati 2010, h.2) mengemukakan bahwa kebijakan hutang ialah bagaimana Sebuah perusahaan dalam melakukan suatu Tindakan untuk mengambil Langkah atau suatu keputusan dalam memperoleh dana baik itu dengan cara menerbitkan sebuah obligasi / surat hutang, saham maupun laba perusahaan harus di tahan.

DERit $=$ Total Hutangit

Total Ekuitasit 


\section{B. Profitabiitas}

Dalam penelitian ini tingkat profitabilitas dapat dikur dengan mneggunakan rasio pengembalian atas asset atau Return On Aset (ROA) Menurut Brigham dan Houston (2010, h.148) dalam Dinar Damayanti dan Hartini (2012), ROA adalah Rasio laba bersih terhadap total asset. Rumus ROA sendiri adalah sebagai berikut

$$
\mathrm{ROA}=\frac{\text { Laba Bersih } \times 100 \%}{\text { Total Aset }}
$$

\section{Ukuran Perusahaan}

Skala perusahaan secara serta merta menggambarkan tinggi ringkasnya kegiatan proses satu perusahaan. Pada biasanya semakin berkembangnya suatu perusahaan hingga akan semakin berkembang pula kegiatannya. Dengan demikian, ukuran perusahaan juga dapat dikaitkan dengan besarnya kekayaan yang dimiliki oleh perusahaan (Mersi Narita 2012, h.2) dalam Damayanti dan Hartini (2012). Selama observasi ini skala perusahaan ditakar melalui memanfaatkan leisure time natural dari total asset. Ukuran perusahaan dinyatakan dengan rumus:

Size $=$ Ln Total Asset

\section{Likuiditas}

Riyanto (2008,h.25) mengutarakan bawah current ratio yakni suatu rintangan yang berkenaan demi kapasitas suatu industri agar suatu tanggung jawab terlaksana. Jenis rasio Likuiditas Dalam penelitian ini menggunakan Current Ratio (CR)

$$
\text { Rasio Lancar }=\frac{\text { Aktiva Lancar }}{\text { Utang Lancar }}
$$

\section{E. Pertumbuhan Penjualan}

Pertumbuhan penjualan merupakan sebuah permintaan indicator serta daya saing sebuah perusahaan dalam dunia industries. Kecepatan progress suatu industry akan membagikan sebuah dampak terhadap kapasitas suatu industry akan berjuang mempertahankan surplus yang sudah pernah di terima sepanjang untuk membiayai keperluan di masa yang akan tiba. Menurut Sayuthi dan Rayithari (2013) mencerminkan bahwa sebuah manifestasi yang dilakukan oleh sebuah perusahaan akan digunaka sebagai prediksi untuk pertumbuhan yang akan datang.

Sales Growth $=$ Sales t- Sales t -1

Sales t-1 


\section{F. Struktur Aset}

Struktur asset merupakan seberapa besar penentuan alokasi dana yang di berikan untuk tiap-tiap elemen asset, baik itu asset lancar maupun asset tetap. Struktur asset Menurut Hidayat (2013) ialah asset tetap di bandingkan dengan total asset yang dimiliki oleh suatu industri

$\mathrm{STA}=$ Aset tetap

Total Aset

\section{HASIL}

Tabel 1. Analisis Statistik Deskriptif

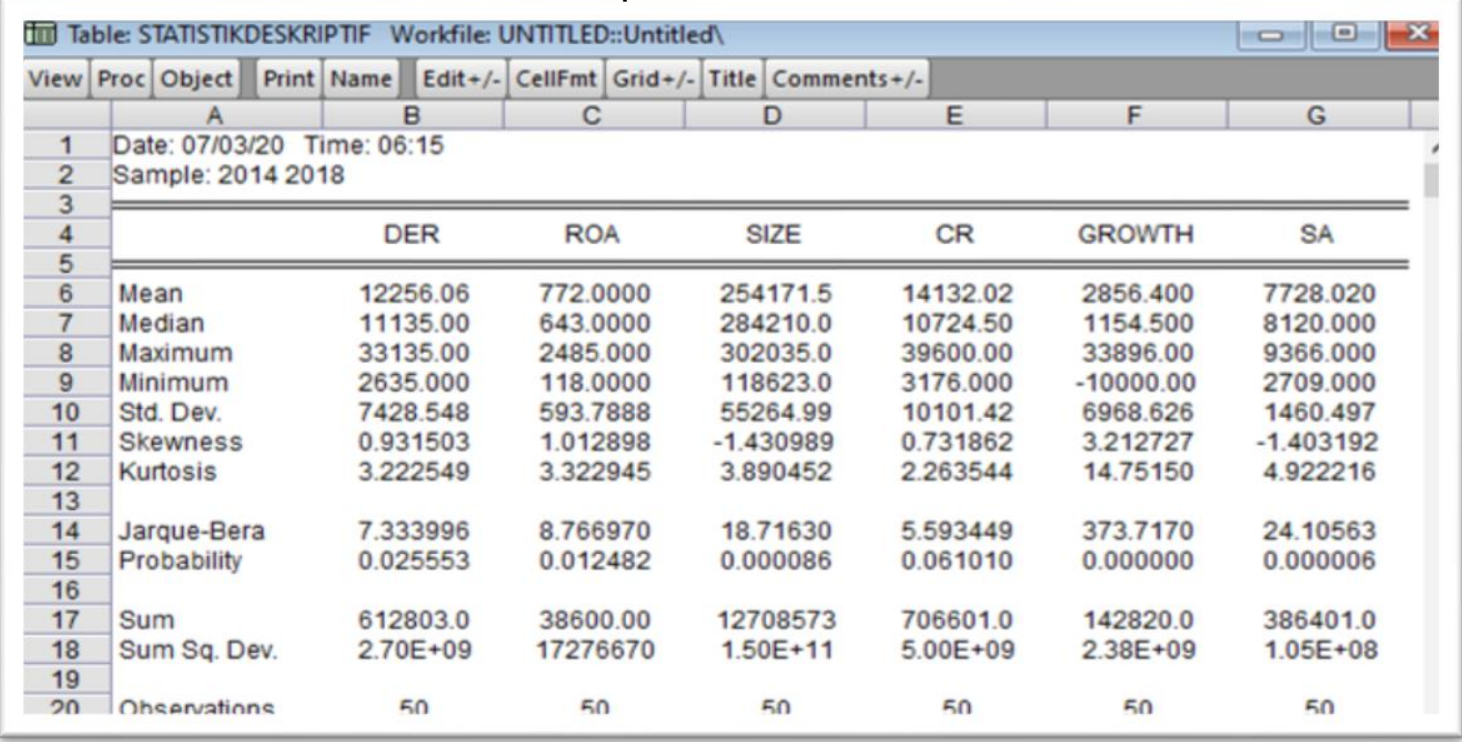

Sumber: Hasil Olahan Eviews 10.0, 2020.

Pemilihan Model Regresi Data panel

Tabel 2. Uji Chow

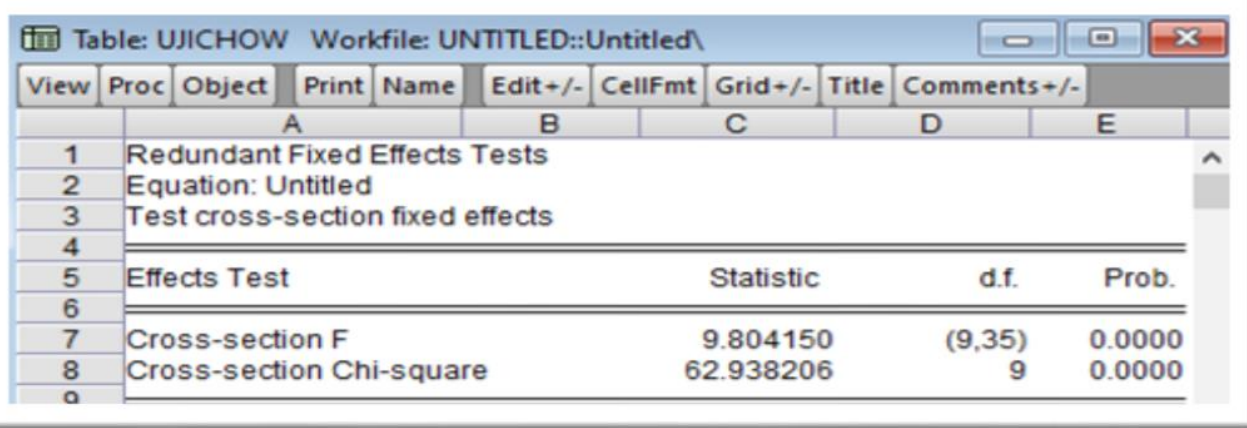

Sumber: Hasil Olahan Eviews 10.0, 2020. 
Tabel 3. Uji Hausman

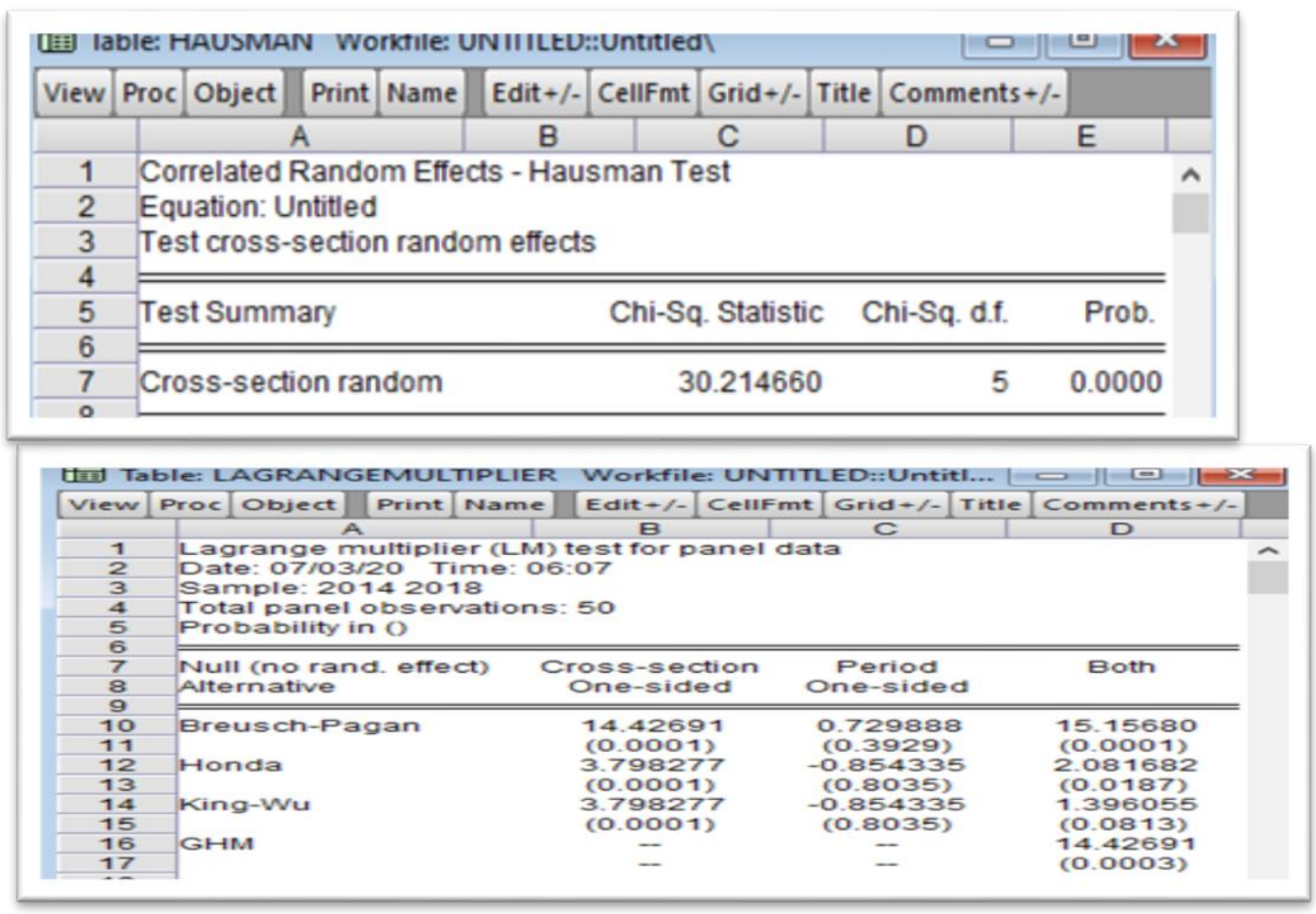

Sumber: Hasil Olahan Eviews 10.0, 2020.

\section{Kesimpulan Model}

Berdasarkan pengujian yang sudah dilakukan maka dapat disimpulkan bahwa Model Regresi Data panel yang akan digunakan dalam Uji Hipotesis dan Persamaan Regresi Data Panel yaitu Fixed Effect Model (FEM), maka perlu dilakukan Uji Asumsi Klasik.

Tahel 5 I lii Multiknlineritas

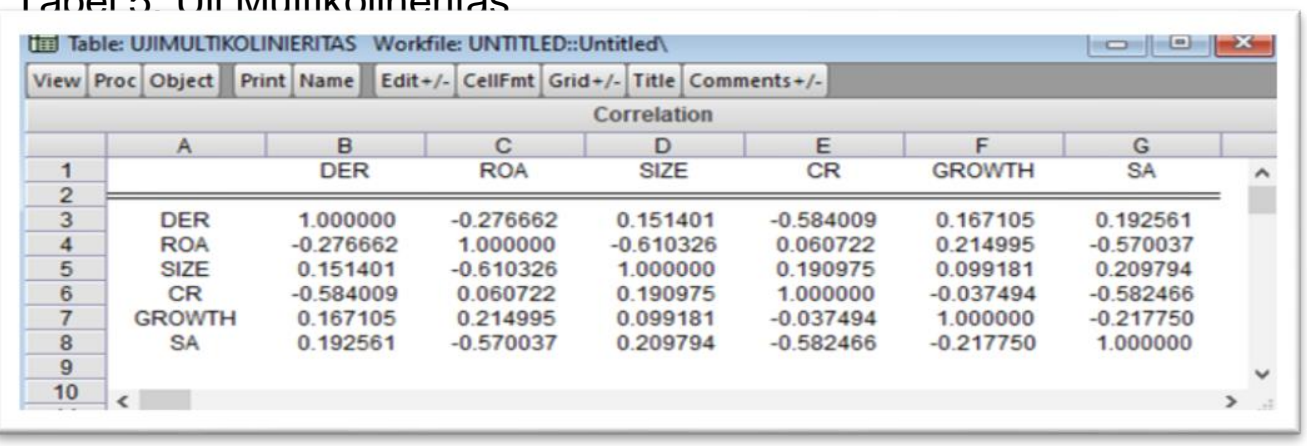

Sumber: Hasil Olahan Eviews 10.0, 2020.

Berdasarkan tabel diatas, dapat dilihat bahwa tidak terdapat variabel independen dengan nilai lebih tinggi dari 0,08 , sehingga dapat disimpulkan bahwa dari data tersebut tidak terjadi multikolinieritas dalam model regresi. 
Tabel 6. Uji Heteroskedastisitas

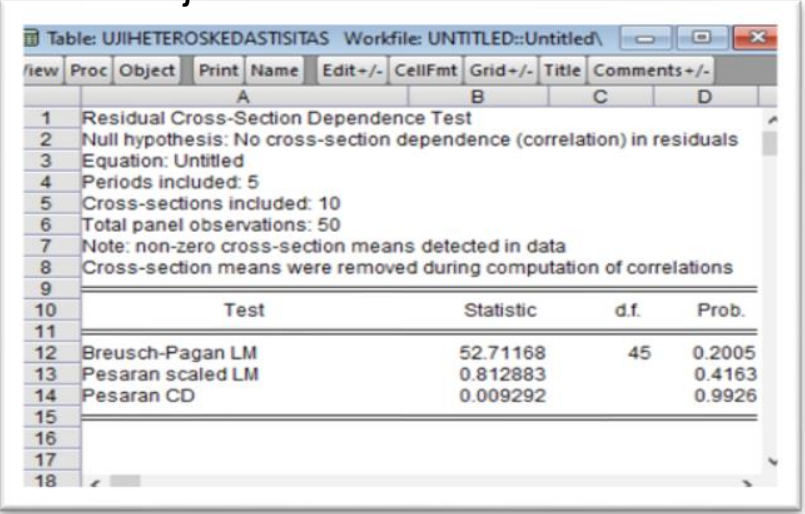

Sumber: Hasil Olahan Eviews 10.0, 2020.

Berdasarkan table diatas, dapat dilihat bhawa nilai Breusch-Pagan LM $>\alpha$ 0,05, maka, dapat disimpulkan bahwa HO diterima yang artinya tidak terjadi heteroskedastisitas pada data panel.

Table 7. Uji Kelayakan Model (F)

\begin{tabular}{|lrll|}
\hline R-squared & 0.894429 & Mean dependent var & 12256.06 \\
Adjusted R-squared & 0.852200 & S.D. dependent var & 7428.548 \\
S.E. of regression & 2855.886 & Akaike info criterion & 18.99548 \\
Sum squared resid & $2.85 E+08$ & Schwarz criterion & 19.56908 \\
Log likelihood & -459.8869 & Hannan-Quinn criter. & 19.21391 \\
F-statistic & 21.18067 & Durbin-Watson stat & 1.572282 \\
Prob(F-statistic) & 0.000000 & & \\
\hline \hline
\end{tabular}

Sumber: Hasil Olahan Eviews 10.0, 2020.

Berdasarkan table uji f nilai F-statistic sebesar 21.18067, sementara FTabel dengan tingkat $\alpha=5 \%$, df1 $(k-1)=5$ dan df2 $(n-k)=55-6=44$ didapat nilai $F$ Tabel sebesar 2.43. Dengan demikian F-statistic (21.18067) > F Tabel (2.43) dan nilai Prob(Fstatistic) $0.000000<0,05$ maka dapat disimpulkan bahwa Ha diterima (pengaruh)

Table 8. Uji T Parsial

\begin{tabular}{crrrr} 
Variable & Coefficient & Std. Error & t-Statistic & Prob. \\
\hline \hline C & 25769.72 & 13334.94 & 1.932496 & 0.0614 \\
ROA & -1.169669 & 1.337046 & -0.874816 & 0.3876 \\
SIZE & 0.026445 & 0.030433 & 0.868955 & 0.3908 \\
CR & -0.350698 & 0.144414 & -2.428417 & 0.0204 \\
GROWTH & 0.006622 & 0.071294 & 0.092885 & 0.9265 \\
SA & -1.862722 & 1.010692 & -1.843016 & 0.0738 \\
\hline
\end{tabular}

Sumber: Hasil Olahan Eviews 10.0, 2020.

Berdasarkan table diatas Nilai t-statistic LIKUIDITAS (CR) sebesar 2.428417, sementara $t$ Tabel dengan tingkat $\alpha=5 \%$, df $(n-k)=44$ didapat 
nilai t Tabel sebesar 2.01537. Dengan demikian t-statistic CR $<\mathrm{t}$ Tabel (2.01537) dan nilai Prob. $0.0005<0,05$ maka dapat disimpulkan bahwa variabel Likuiditas (CR) dalam penelitian ini memiliki pengaruh negatif terhadap Kualitas Laba.

\section{KESIMPULAN DAN SARAN}

Tujuan dari penelitian ini yaitu untuk mengetahui kondisi ekonomi terhadap Kebijakan Hutang pada perusahaan yang terdaftar di Bursa Efek Indonesia sebagai berikut:

1. Profitabilitas

Berpengaruh negative terhadap kebijakan hutang pada perusahaan Customer Good Industries (CGI). Hal ini di tunjukan dengan nilai perhitungan Uji T yaitu sebesar -0,874816.

2. Ukuran Perusahaan

Berpengaruh positif terhadap kebijakan hutang pada perusahaan CGI yang terdaftar di Bursa Efek Indonesia Periode 2014-2018 dimana hasil yang di peroleh dengan uji $\mathrm{T}$ yaitu 0,868955 .

3. Likuiditas

Berpengaruh negative terhadap kebijakan hutang pada perusahaan yang terdaftar di Bursa Efek Indonesia dimana hasil yang di peroleh melalui Uji T adalah sebesar -2,428417.

4. Pertumbuhan penjualan

Berpengaruh positif terhadap kebijakan hutang pada perusahaan CGI yang terdaftar di Bursa Efek Indonesia. Dimana hasil yang di peroleh setelah melakukan Uji T yaitu sebesar 0,092885

5. Struktur asset

Berpengaruh negative terhadap kebijakan hutang pada perusahaan yang terdaftar di Bursa Efek Indonesia. Dimana setelah melakukan Uji T hasil yang di peroleh yaitu sebesar $-1,843016$

Sebelum melakukan penelitan ,sebaiknya pilih judul yang tidak terlalu rumit, dan juga variabel yang tidak terlalu sulit di teliti serta estimasi tahun penelitian di mulai dari 4 tahun minimal, sehingga mudah untuk mendapatkan pengaruh yang signifikan.

\section{DAFTAR PUSTAKA}

https://www.idx.co.id/

Aditama, F. (2015). PENGARUH UKURAN PERUSAHAAN,. 82.

Dinar Damayanti, T. H. (n.d.). Pengaruh Profitabilitas, Likuiditas, Pertumbuhan Penjualan terhadap kebijakan hutang.

Kristina, A. (2019). ANALISIS PENGARUH LIKUIDITAS, STRUKTUR AKTIVA, FREE CASH FLOW DAN UKURAN PERUSAHAAN. keunis Majalah IImiah - ISSN No 2302-9315 Vol. 7 No 2 Thn VII Juli 2019, 7. 
Manoppo1, M. (2012). PENGARUH STRUKTUR ASET TERHADAP KEBIJAKAN HUTANG PADA PERUSAHAAN OTOMOTIF YANG $\begin{array}{llll}\text { TERDAFTAR DI } & \text { BEI PERIODE }\end{array}$ M.Manoppo.,M.Mangantar.,P. Van Rate.,Pengaruh Struktur......, 1796.

Rajagukguk, L. (2017). ANALISIS PENGARUH KEBIJAKAN DEVIDEN, STRUKTUR ASET, DAN PERTUMBUHAN PENJUALAN TERHADAP KEBIJAKAN HUTANG. JURNAL AKUNTANSI, VOL. 17, NO. 1, JANUARI - JUNI 2017, 1.

SUSANTI, F. (n.d.). PENGARUH LIKUIDITAS, KEBIJAKAN DEVIDEN, STRUKTUR ASET, UKURAN PERUSAHAAN DAN PERTUMBUHAN PENJUALAN TERHADAP KEBIJAKAN HUTANG PADA PERUSAHAAN MANUFAKTUR YANG TERDAFTAR DI BURSA EFEK INDONESIA. 